\section{A sociologia interpretativa}

\section{RESUMO}

Neste texto Patrick Tacussel faz uma reflexão a respeito dos caminhos e métodos adotados pela pesquisa francesa na construção de uma sociologia interpretativa.

\section{ABSTRACT}

In this paper the author reflects upon the ways and the methods employed by French researchers who try to found an interpretive sociology.

\section{PALAVRAS-CHAVE (KEY WORDS) \\ - Metodologia (Methodology) \\ - Sociologia interpretativa (Interpretive sociology) \\ - Epistemologia (Epistemology)}

\section{Patrick Tacussel}

Professor de Sociologia - Universidade de Montpellier,

\section{Uma virada pós-empirista nas ciências humanas francesas}

A INFLUÊNCIA DO POSITIVISMO na sociologia francesa transborda o quadro de uma doutrina, nascida em meados do século 19 e cujo interesse hoje é sobretudo museográfico. De fato, quando Auguste Comte sugere a palavra "sociologia", na $47^{a}$ lição de seu Curso de filosofia positiva, em 1839, a física social cede lugar a uma ciência da organização social que deve repousar sobre uma explicação objetiva dos fatos sociais, através do funcionamento das leis do espírito humano. Esse projeto ambicioso obedece em primeiro lugar a considerações de ordem moral e política, pois se trata de integrar os conhecimentos científicos da época em um programa capaz de acompanhar a mutação industrial do Ocidente. A exemplo da maior parte de seus contemporâneos, Comte procura exorcizar a lembrança ainda dolorosa da Revolução Francesa, pensa que as elites devem se beneficiar de um aparato conceitual e metodológico adaptado à missão de reforma pacífica da humanidade. Mais de um século e meio depois, ocorre porém que o balanço da sociologia resta em aberto o problema da unidade da disciplina, consagrado no plano acadêmico desde a época dos trabalhos de Émile Durkheim, e é flagrante a diversidade de seus métodos.

No começo dos anos 60, estando diante da flexibilidade condescendente de sua definição, assiste-se a um recentramento. Georges Friedmann e Pierre Naville, o primeiro na Escola de Altos Estudos em Ciências Sociais, o segundo no Conselho Nacional de Pesquisa Científica, estimulam o engajamento dos pesquisadores com a sociologia empírica, de um modo muito semelhante ao que ocorria nos Estados Unidos, enquanto 
Raymond Aron reafirma a importância de Max Weber e da escola alemã de ciências sociais. O "Grande teórico" e o "hiperempirista", os dois célebres tipos descritos por C. Wright Mills, se encarnam nessas tendências. As conseqüências culturais e as repercussões teóricas dos acontecimentos de maio-junho de 68 no campo das ciências humanas jogaram um papel de aceleradores de um processo de auto-reflexão, destacado por R. Aron em 18 lições sobre a sociedade industrial'1.

A exploração antropológica do imaginário, a sociologia da vida cotidiana e a reflexão epistemológica sobre a complexidade das formas sociais [aparecida desde então] indicam uma virada pós-empirista nas ciências humanas. O estabelecimento da prova através da pesquisa sociográfica deixou de aparecer como um objetivo essencial. $O$ estudo do sentido vivido das relações intersubjetivas desenha um quadro interpretativo que via de regra apela à fenomenologia e à hermenêutica contemporâneas e, assim, a noções mutantes, oriundas de domínios culturais variados (estética, gênero literário, ficção, etc.).

\section{A socioantropologia do imaginário social}

A consideração dos processos imaginais na vida social corresponde, na sociologia, à descoberta científica do inconsciente para a psicologia ou a filosofia. O imaginário se apresenta como um trajeto do psíquico para o social-histórico, revelando "verdadeiras infra-estruturas do espírito coletivo" 2; ele permite analisar os fatos e eventos sociais através das crenças. Representações e sentimentos comuns; enfim, ele desemboca sobre a tomada em consideração epistemológica dos elementos simbólicos em ação nos regimes de pensamento (racional, mítico, ideológico, religioso, etc.). Nesse sentido, a sociologia do imaginário é um setor da antropologia social e cultural; reabilitando a função da imagem no plano cognitivo, ela retoma os trabalhos de Gaston Bachelard, Roger Bastide ou Claude LéviStrauss. As estruturas antropológicas do imaginário, essa síntese empreendida por Gilbert Durand, não por acaso estão na origem de seu desenvolvimento. Seguindo esse autor, entende-se por hermenêutica instauradora um trabalho de leitura e de classificação da atividade simbólica, observável, por exemplo, nos ritos ou nas liturgias (culturais, políticas, etc.) e nas expressões contemporâneas dos modos de vida (a publicidade, o cinema, a fabricação tecnológica de espaços virtuais...). A sociedade é apreendida como um texto que é alimentado sem cessar pelas significações veiculadas pela experiência coletiva. Essas últimas são articuladas em torno de três esquemas que enquadram a polarização das imagens: a separação (o heróico), a inclusão (a mística) e a dramatização (a disseminação). O eu social visto pois como um esforço permanente de apropriação pela conduta, os papéis e as aparências educadas, da esfera das regras, códigos e das leis (o superego imaginário), edificado sobre o solo do "isso antropológico" ou inconsciente coletivo, caracterizado pela invariância mítica e as "imagens arquetípicas" (C.G. Jung).

Essa perspectiva representa 0 aprofundamento de uma direção que Durkheim havia sintetizado o programa já em 1898, em "Representações individuais e representações coletivas" ${ }^{3}$. $\mathrm{Na}$ mesma época, Georges Sorel insiste sobre a importância dos mitos no mundo moderno, destacando seu dinamismo, que se liga ao movimento da vida afetiva e inventa um cenário para a ação ${ }^{4}$. Para esses dois autores, os acontecimentos cuja memória partilhada fixa a lembrança adquirem uma posição emblemática ou lendária através das representações imaginárias que difundem. Existe uma correlação entre a realidade social e a potência concreta do simbólico, e essa não se reduz à ilusão 
ou a ocultação/deformação de relações ou de fatores objetivos existentes nas relações socioeconômicas. Os trabalhos de Maurice Halbwachs, os quadros sociais da memória ou La topographie légendiare des Evangiles en Terre Sainte ${ }^{5}$ mostram que a superioridade do fato social sobre a atitude individal não é uma questão de liberdade ou de vontade coatadas, mas o resultado de uma coesão que solda as crenças e as práticas no seio de uma instância de referência e adesão culturais ou mentais (o povo, a nação, a tribo, a comunidade, etc.). É isso que explica por que as condutas sociais obedecem a imperativos simbólicos que traduzem e ultrapassam os interesses ou valores existentes em dado momento. Nesse quadro, a ideologia não é mais essencialmente uma amplificação política ou histórica da falsa consciência, mas uma derivação particular de construções míticas que reproduzem na existência coletiva suas funções específicas: hierarquizar/ invalidar; incluir/excluir; ordenar/separar, etc. Essas últimas ostentam o destino do grupo a partir de uma temporalidade da qual elas asseguram o domínio com base nas esperanças, temores ou momentos exemplares do passado.

O livro de Roger Caillois: Instincts et société: Essai de sociologie contemporaine ${ }^{6}$ merece ser citado como trabalho precursor neste domínio. Ele demonstra que "não há sociedade totalmente dominada pela potência da abstração, porque o mito e as realidades que lhe dão origem perderiam então todo o direito e poder"7. Longe de se ausentar em uma civilização materialista ou mercantilista, o sagrado, a magia e o maravilhoso irrompem no campo do domínio político sob a figura do chefe carismático, com a solidariedade sem concessão do "espírito de seita", no tratamento dos fait-divers que torna o imaginário mais sólido e resistente que o real, tornado frágil e difuso, pela imprensa, ou ainda na produção cinematográfica, "meio de expressão privilegiado da sensibilidade coletiva", conclui Caillois ${ }^{8}$.
Em seu ensaio "Cinema: o homem imaginário"9, Edgar Morin mostra como a imagem, "ato que de maneira radical e simultânea constitui o real e o imaginário"10, organiza nossa relação com o mundo. Segundo ele, o cinema ilustra uma necessidade elementar da sociedade, a necessidade de ficção; através de sua evocação e de sua cintilação, ou de seus ideais encarnados (as estrelas) ${ }^{11}$, a representação cinematográfica opera uma transição em direção ao sonho, desvia-se da percepção em estado de vigília em direção de um imaginário, latente nos símbolos e concretizado no produto estético, em torno do qual se manifesta uma participação efetiva (e afetiva). A importância do imergido ou ainda não consciente no universo social é igualmente atestada pelo exame da "virulência eventual" (rumores, lendas urbanas, fatos pitorescos, etc.), que fazem ressurgir um fundo arcaico, mitológico e estranho no interior dos acontecimentos contemporâneos. Baseado nisso, Edgar Morin elaborou os princípios de uma sociologia do presente, atenta às crises deslanchadas pela tensão entre um processo de racionalização e seus contra-efeitos problemáticos: inquietude, angústia, revoltas, pesquisa de "culpados", etc. ${ }^{12}$. La Rumeuer d'Orléans, publicado em 1969, é uma pesquisa de campo que se tornou exemplo clássico de metodologia nesta abordagem. Analisando a propagação de uma falsa notícia delirante (o desaparecimento de meninas nos provadores de lojas de comerciantes judeus de uma cidade de porte médio francesa), o sociólogo e sua equipe estudam o ciclo do rumor que converte o "disse por aí" em certeza e, depois, em acusação. No curso desse trajeto narrativo, o fantasma se transmuta em mito e assume uma extensão perversa, como se fosse uma metástase patológica. Na consciência coletiva, ocorreu que "uma história fabulosa se transformou em pseudo-acontecimento histórico"13. Numa escala mais ampla, certas formas 
de legitimação do poder político recorrem a montagens similares: as "religiões políticas", com suas encenações, seus ritos e emblemas, funcionam com base no modelo de experimentação especificamente irracionais, que visam a provocar um fervor massivo na população ${ }^{14}$. Lado a lado com o mito do progresso e das utopias, contam-se entre as principais recorrências imaginárias do pensamento político: a decadência, o homem novo, o salvador, o eleito ou o povo eleito, o complô. A propósito, a maneira como os livros escolares contam a história segue sendo uma fonte de pesquisa e de documentação sobre as interferências míticas na memória coletiva. O estudo da vida cotidiana também confirma a "pregnância simbólica" existente no que os sociólogos P. Berger e T. Luckmann chamam de construção social da realidade.

\section{A sociologia compreensiva da vida cotidiana}

Desde meados do século 20 , a vida cotidiana se tornou objeto de considerável número de trabalhos. Os historiadores foram os primeiros a entrever que a existência corrente ou "banal" não era apenas o envelope alienado das relações sociais. Com o enfraquecimento do enfoque crítico segundo o qual a alienação era o fator central da cotidianidade (Henri Lefèbvre, Agnès Heller, Herbert Marcuse, Karel Kosik, Guy Debord ...), uma outra atitude, compreensiva, se impôs: metacrítica (Jean Baudrillard), formista (Michel Maffesoli) ou figurativa (Pierre Sansot, Patrick Tacussel), reatando-se as filiações intelectuais com o legado de Georg Simmel, a fenomenologia contemporânea de Alfred Schütz, o interacionismo e a etnometodologia, sem esquecer as pesquisas antes apresentadas de Edgar Morin.

Entre 1937 e 1938, o Colégio de Sociologia, fundado por Georges Bataille, Roger Caillois e Michel Leiris, atribuiu-se a missão de refutar a covardia intelectual "contemporânea de uma ideologia que estranhamente nega os fenômenos de atração e de coesão instintivos, onde se pode pesquisar a força viva dos agrupamentos sociais"15.

Desde então, a questão do individualismo e da supersocialização passou a ser vista do ângulo da medida da singularidade do ser diante das escolhas e pesos de sua ação. É o caráter indissolúvel de uma comunidade que preside ao enquadramento das reações pessoais imediatas e reduz as forças de dispersão sociais. Entre as contribuições mais notáveis dessa associação original, freqüentada por Walter Benjamin, Max Horkheimer e Theodor Adorno, pode-se consultar: La Sacré dans la vie quotidienne, de M. Leiris, Le vent d'hiver, de R. Caillois, La structure des démocraties e Strutucture et fonction de l'armée, de G. Bataille, Sociologie du bourreau, de R. Caillois. A diversidade de temas abordados obedece à preocupação fundamental: identificar na existência social os fenômenos elementares de atração e de repulsão que a comandam, e observar sua concretização nas instituições onde a atividade total do sujeito parece ser absorvida da maneira mais flagrante (os exércitos, as igrejas, os partidos políticos, as seitas, etc.). Esse enfoque, à época muito marginal, encontrase presente mais ou menos explicitamente em numerosos trabalhos contemporâneos e lhe imprimem um estilo reconhecível. A obra de Jean Duvignaud, ampliando no sentido do conjunto da vida social (ritos religiosos, ritos laicos, jogos, festas, etc.) a idéia de encenação a partir da sociologia do teatro ${ }^{16}$, ou o ensaio de Georges Auclair, que estudou a fascinação e o temor que exerce a transgressão de normas coletivas, provêm dessa tradição ${ }^{17}$. Jean Duvignaud a descreve como uma hermenêutica inclinada ao deciframento das imagens exasperadas que, clandestinamente, modelam os comportamentos sociais e definem um espaço onde o desejo confere preço às coisas sem preço ${ }^{18}$. 
Aparecido um pouco antes de maio de 1968, o primeiro ensaio de Jean Baudrillard interroga essa insólita familiaridade que mantermos com os objetos que nos cercam:

"Quais necessidades outras que as funcionais respondem os objetos, quais estruturas mentais se misturam com as estruturas funcionais e com elas entram em contradição, sobre qual sistema cultural, infra ou transcultural se funda sua vivência cotidiana?"19.

O sociólogo responde que todos esses objetos habituais (bibelôs, móveis, veículos, aparelhos domésticos, etc.) constituem um sistema de signos sociais; eles são consumidos mais por seu valor social do que por seu valor de uso funcional. Neste espírito, ele assegura que nossa prática cotidiana introduz o objeto não no contexto de uso ou de satisfação de uma necessidade, mas numa relação com todos os outros objetos-signo: "O consumo, embora tenha um significado, é uma atividade de manipulação sistemática de signos"20. J. Baudrillard dará um acabamento sistemático a essa tese nas obras que seguirão a essa: A sociedade de consumo, Por um crítica da economia política do signo e $\mathrm{O}$ espelho da produção ${ }^{21}$. Depois disso, não se pode mais opor a utilidade ao intercâmbio, pois essa utilidade - como a própria noção de necessidade - está ela mesma ligada ao sistema de troca. Visando a quebrar o valor de troca, é preciso restituir a troca, e não o valor (ainda que de uso).

Partindo de uma reflexão sobre as metamorfoses da violência nas suas relações com a estruturação da ordem social, as pesquisas de Michel Maffesoli respondem à questão: por onde (e como) se regenera a potência do estar-junto, do ser-em-conjunto, ou, dito de outro modo, do consensus, que assegura o equilíbrio da existência em sociedade? O sociólogo vê na permanência da socialidade, isto é, na vida cotidiana mais banal, uma intensidade oculta que afronta os poderes administrados e as conseqüências mais coatoras da socialização. Diante dos excessos da dominação, dos diversos imperativos exteriores (o trabalho, a moral, etc.), o homem comum esconde sob o manto das aparências sua pertença ao mundo vivido socialmente, feito de instantes onde se cristaliza a autêntica significação da vida ${ }^{22}$.

Com A conquista do presente (1979), M. Maffesoli dirige seu olhar em direção da teatralidade social que, sob traços ordinários, lúdicos ou festivos, exprime uma aceitação trágica e um enfrentamento do destino e, igualmente, o investimento individual em uma realidade comunitária (a amizade, a cumplicidade dos "bandos" ou dos grupos de afinidade, as solidariedades minúsculas ...). Nesta ótica, ele insiste em seguida sobre as figuras da efervescência (a festa, a orgia, o gasto). Em contraponto ao mito prometéico - a domesticação racional da natureza - assistimos, segundo ele, a um retorno dos valores dionisíacos, os quais escondem uma lógica das paixões que ultrapassa o quadro das práticas sexuais. Essa exacerbação dos afetos se enraiza em uma centralidade subterrânea, característica da pós-modernidade, e cujas formas tribais de agregação, por exemplo: as juvenis, constituem um indício sociológico. Essa visão acaba relativizando a tendência individualista, rapidamente notada por vários observadores, em benefício de uma ecologia geral das relações intersubjetivas, baseada na estilização dos comportamentos, no gosto de viver as situações e as oportunidades do jogo existencial de maneira presenteísta 23 .

Do nomadismo, vagabundagens iniciáticas, recente livro do autor, ambiciona assinalar as múltiplas facetas da errância, a fim de restituir a esse fenômeno sua dignidade antropológica. Michel Maffesoli mostra que, abandonando as certezas costumeiras de seu ambiente, 
- viajante engaja seu espírito e sua vontade no âmbito de novas extensões, que desvelam o mistério de seu estarno-mundo. Descobrindo outros lugares, ele se reencontra na diversidade das culturas e explora a existência naqueles "estados múltiplos" de que falava René Guenon... Saber semelhante não obedece a nenhuma autoridade particular, exceto a da perfeição de si, e trata-se de uma busca que longe está de ser um obstáculo à compreensão dos outros. Ao contrário, ela impulsiona um "hedonismo relativo", para retomar a expressão do sociólogo; isto é, uma espécie de utopia da relação e da coabitação, que funda o instinto gregário, o prazer do estar junto gratuitamente. Através da pesquisa de emoções voluptuosas e do desenraizamento, o sujeito errante renasce, a vida aparece como mapa dobrado de momentos vividos, frágeis e ainda possíveis. Nisso a viagem é iniciática, coloca o sujeito à prova do desconhecido e do imprevisível, obrigando-o a encontrar os sinais de uma eventual hospitalidade. O nômade exprime, em toda a sua força, o desejo de circular livremente, uma pulsão irrepreensível que transforma cada partida em sonho de um horizonte anunciador de uma nova despedida.

\section{Conclusão: um arco epistemológico}

Concluindo, gostaríamos de indiciar muito brevemente um arco epistemológico que poderia sintetizar a originalidade dos caminhos que acabamos de descrever. Como chama a atenção Michel Maffesoli, a pós-modernidade é menos um conceito do que uma categoria existencial que designa uma estética ampliada aos diversos domínios da existência; ela dá conta da valorização do doméstico, remete a uma ética emocional, ao ajustamento contemporâneo entre o arcaico e as tecnologias mais avançadas (informática, imagens virtuais, etc.), sem excluir o nãoracional, até então mantido à margem da consagração do sujeito enquanto homo oeconomicus ou homo politicus. Reencontramos aqui uma das proposições fecundas de Georg Simmel, segundo a qual "quanto mais complexas são as figuras que nossa intuição é capaz de apanhar, mais a aplicação de categorias estéticas se distancia das figuras individuais, perceptíveis pelos sentidos, em direção às figuras sociais" 24 . Sob o termo formismo, Michel Maffesoli procura atualizar a concepção simmeliana de sociologia: evitar o fantasma da clausura, reconhecer a singularidade, respeitar 0 detalhe e o múltiplo, fazer despontar a aventura do cotidiano como criação coletiva por "aproximações sucessivas" - é por essa via que o sociólogo nos convida a apreciar a forma em sua relação com o tipo-ideal weberiano, o resíduo em V. Pareto ou a tipicalidade em A. Schütz.

A analogia formista procura compreender a correspondência física e social, isto é, a interdependência dos fatores que comandam a lógica do ser vivo. Esse enfoque converge com o do paradigma da complexidade, explorado por Edgar Morin. O complexo combina ordem e desordem, a interação e a organização: por isso não se deixa reduzir epistemologicamente a um esclarecimento analítico monocausal ou determinista. $O$ efeito escapa à causa ou retroage sobre ela. Edgar Morin explica que cada elemento de um sistema se integra, relativizandose, no seio de um meta-sistema, que transforma cada um deles no curso de um processo de encadeamento retroativo e recursivo ${ }^{25}$. Complexidade e forma, o cabo e a corda, não são elas bem a imagem de um mundo cujas extremidades são ao mesmo ligadas e maleáveis? A metáfora do arco epistemológico, que as associa, se adapta a essa hipótese porque permite dar conta de uma realidade social que ao mesmo tempo se baseia na materialidade dos fatos sociais e se projeta no céu enuviado das representações, dos mitos e dos símbolos. 
Este artigo foi originalmente escrito como "La sociologie interpretative: un tournant post-empiriste dans les sciences humaines en France". Traduzido por Francisco Rüdiger. Patrick Tacussel é Diretor do Instituto de pesquisas sociológicas e antropológicas - IRSA - da Universidade de Montpellier III (França).

\section{Notas}

1 Aron R. (1972), Dix-huit leçons sur la société industrielle, Paris, Gallimard, coll. Idées, p.14.

2 Pessin A. (1992), Le mythe du peuple et la société française au XIXe siècle, Paris, P.U.F, p.36.

3 Durand G. (1993 a).

4 Durkheim E. (mai 1898), Représentations individuelles et représentations colletives, Revue de métaphysique et de morale, T. VI, Paris; également, Sociologie et philosophie, chapitre premier.

5 Sorel G. (1907), Réflexions sur la violence, introduction.

6 Halbwachs M. (1925), les cadres sociaux de la mémoire, réed. (1994), Paris, Albin Michel.

Halbwachs M, (1941), La topologie des Evangiles en Terre Sainte. Etude de mémoire collective, Réed, (1972), Paris, Puf.

7 Caillois R. (1964 c).

8 Caillois R. op. cit. p.34.

9 Caillois R. idem. Op. cit. p.128.

10 Morin E. (1954), Le cinéma ou l'homme imaginaire, Paris, ed. de Minuit.

11 Morin E. (b), op.cit, p. XI.

12 Morin E. (1972), Les stars, Paris Seuil.

13 Morin E. (1982), La rumeur d'Orléans, Paris, Seuil, p.245 à 253.

14 Morin E. La rumeur d'Orléans, op. cit. p. 37.
15 Rivière C. (1988), Les liturgies politiques, Paris, Puf.

16 Caillois R. (1979) "Le vent d'hiver", p.79, in Denis Hollier, Le Collège de Sociologie, Paris, Gallimard, coll. idées 413.

17 Duvignaud J. (1965), Sociologie du théâtre, Paris, Puf. Duvignaud J. (1970), Spetacle et Société, Paris, DenoëlGonthier.

Duvignaud J. (1977), Le Don du Rien, Paris, Stock.

Duvignaud J. (1986), L'Anomie, Paris, réed. La Découverte.

18 Auclaire G. (1970), Le "Mana" quotidien. Structures et fonctions de la chronique des faits divers, Paris, Anthropos, 2 ed. (1982).

19 Duvignaud J. (1990 a).

20 Baudrillard J. (1976 a ).

21 Baudrillard J. (a), op. cit. p. 233.

22 Baudrillard J. (1976 b)

Baudrillard J. (1972), Critique de l'économie politique du signe, Paris, Gallimard.

Baudrillard J. (1985 c)

23 Maffesoli M. (1979), La violence totalitaire, Paris, réed. (1993), Méridiens-Klinckieck.

Maffesoli M. (1984), Essai sur la violence banale et fondatrice, Paris, Librairie des Méridiens.

24 Maffesoli M. (1979 a).

Maffesoli M. (1988 c).

Maffesoli M. (1982 b).

Maffesoli M. (1992), La transfiguration du politique, Paris, réed. Le Livre de Poche (1995).

25 Maffesoli M. (1997), Du Nomadisme, Vagabondages initiaques, Paris, Livre de Poche.

26 Simmel G. (1896), "Esthétique et sociologie", trad. franç. in La tragédie de la culture et autres essais, Paris, Rivages, (1988), p. 131.

27 Morin E. (1977), Lá méthode. 1, La nature de la nature, Paris, Seuil, p. 381. 


\section{Referências}

Baudrillard J. (1968 a), Le système des objets, Paris, Gallimard.

Gallimard.

(1976 b), La société de consommation, Paris, Gallimard.

(1976 b), L'échange symbolique et la mort, Paris, (1985 d), Le miroir de la production, Paris, Galilée.

(1987 e), La transparence du mal, Paris, Galilée.

Caillois R. (1972), Le mythe et I'homme, Paris, Gallimard. . (1967 b), Les jeux et les hommes, Paris, Gallimard. .(1972 c), Le mythe et l'homme, Paris, Gallimard.

Campion-Vincent et Renard J. B. (1992), Légends urbanies, Paris, Payot, réed. (1998).

Desroche H. (1973 a), Sociologie de l'espérance, Paris, Calmann-Lévy.

Durand G. (1984), L'imagination symbolique, Paris, Puf.

.(1993), Les structures anthropologiques de l'imaginaire, Paris, Dunob, 11 ed.

. (1994 c) L'imaginaire, Paris, Hatier.

Duvignaud J. (1990 a), La genèse des passions dans la vie sociale, Paris, Puf.

Hollier D. (1979), Le Collège de Sociologie, Paris, Gallimard, coll. Idées 413 .

Maffesoli M. (1979), La conquête du présent, Paris, Puf, réed, Paris, Desclée de Brouwer, (1998)

- (1982 b), L'ombre de Dionysos, réed, Paris, Livre de Poche, (1991).

(1988 c) Le temps des tribus,Paris, Le Livre de

Poche, (1991).
Tacussel P. (1984 a), L'attraction sociale. La dynamique de l'imaginaire dans les sociétés monocéphales, Paris, Libraire des Méridiens.

- (1995 b), Mythologies des formes sociales, Paris, Méridiens-Klincksieck.

Brouwer. (1999 c), Le jeu des passions, paris, Desclée de

Watier P. (1996), La sociologie et les représentations de l'activité sociale, Paris, Méridiens_Klincksieck. 